\title{
Meta-analysis of the role of oral contraceptive agents in inflammatory bowel disease
}

\author{
P G Godet, G R May, L R Sutherland
}

\begin{abstract}
Numerous epidemiological studies have been performed to determine factors that might contribute to the development of inflammatory bowel disease. Although the role of oral contraceptive agents in Crohn's disease (CD) and ulcerative colitis (UC) have been assessed, most studies were of small sample size and characterised by low statistical precision. A meta-analysis was performed to increase the statistical power and to investigate the association between the use of oral contraceptives and the development of $\mathrm{CD}$ and $\mathrm{UC}$. The study was based on a search of a Medline database from 1975 to October 1993 and a review of reference lists from published articles, reviews, symposia proceedings, and abstracts from major gastrointestinal meetings. All studies specifically designed to evaluate this association were selected. The combined results of nine studies - two cohort studies (30 379 unexposed and 30673 exposed patients) and seven case-control studies (482 CD, 237 UC, and 3198 controls) - which satisfied our selection criteria were evaluated. The pooled relative risk (adjusted for smoking) associated with oral contraceptive use was $1.44(1 \cdot 12$, 1.86) for CD and $1.29(0.94,1.77)$ for UC. These results suggest modest associations between the use of oral contraceptives and the development of CD and UC. As these associations are weak, non-causal explanations for the findings cannot be eliminated.
\end{abstract}

(Gut 1995; 37: 668-673)

Keywords: inflammatory bowel disease, oral contraceptives, meta-analysis.

Numerous epidemiological studies have been performed to determine factors which might contribute to the development of Crohn's disease (CD) and ulcerative colitis (UC). Although many factors have been suggested, including smoking, family history, geographic location, socioeconomic status, diet, and oral contraceptive agents, only the first two factors have a firmly established association. ${ }^{1-4}$ Many case reports have been published since 1970 suggesting a possible causal association between the use of oral contraceptives and a Crohn's like disease which was reversible after stopping oral contraceptives. ${ }^{5-10}$ Furthermore, histopathological studies have proposed a pathogenic model in which $C D$ might be caused by multifocal infarction in which smoking and oral contraceptives act as potentially thrombogenic agents. ${ }^{11} 12$
Recent epidemiological studies have assessed the role of oral contraceptives in CD or UC, or both. ${ }^{13-27}$ Most of these studies, however, were of small sample size and characterised by low statistical power. We therefore performed a meta-analysis to increase the statistical power to address this important clinical question. Our primary objective was to investigate the association between the use of oral contraceptives and the development of CD and UC.

\section{Methods}

We performed a meta-analysis, based on a search in English and French language using a Medline database under the list terms 'Crohn's disease', 'ulcerative colitis', or 'inflammatory bowel disease' and 'oral contraceptive agents' from 1975 to 1993 . We also reviewed reference lists from published articles, reviews, symposia proceedings, and abstracts from major gastrointestinal meetings. We selected all casecontrol and cohort studies specifically designed to evaluate this association. An acceptable comparison group had to be formed by either a non-user population (cohort studies) or by inpatients, outpatients, or neighbours of the cases (case-control studies). The identification of women as never, ever, or current users was not required for this analysis, although most of the studies provided this information. No restrictions were imposed for the method by which information was obtained (by mail, phone, or interview in all studies) or the number of subjects in the comparison group.

While the use of prevalent cases may generate a recall bias, ${ }^{28}$ studies using this methodology have taken precautions to minimise bias (for example, including only patients with disease onset within three or four years of interview ${ }^{21}$ or by confirming data obtained by questionnaire with data from review of the charts of patients and controls ${ }^{27}$ ). The use of incident cases would be preferable but inflammatory bowel disease is not common enough to allow a single investigator such an approach.

\section{Statistical methods}

To pool relative risks (RR) from several studies, we used a meta-analytic method ${ }^{29}$ that yields a weighted average of the log $R R$ from the individual studies, in which the weight depends on the inverse of the variance of the $\log R R^{29-31}$ This approach gives larger studies greater weight in the summary measure. To convert confidence intervals (CI) from the different studies into estimates of the variance of the $\log R R$ to the $\log$ scale, we assumed that 
the $95 \%$ CI was obtained by adding and subtracting 1.96 times the standard error of the $\log R R$. We divided the interval length by 3.92 to obtain an approximate standard error.

Although we combined the results from cohort and case-control studies when possible, we evaluated separately the effect of oral contraceptives for CD and UC. We distinguished between studies that were adjusted for smoking and those which were not. Although the results will be reported separately for subgroups, we tested for homogeneity ${ }^{29}$ for each subgroup. Potentially, heterogeneity may result when results from studies giving rates adjusted only for smoking are combined with studies adjusted for smoking, diet, and education. The statistical tests for homogeneity gave $\mathrm{p}$ values greater than 0.30 for $C D$ studies adjusted for smoking, for $\mathrm{CD}$ studies unadjusted for smoking, and for UC studies adjusted for smoking. We thus assumed that existing heterogeneity between studies was small enough to be reasonably ignored. Homogeneity has not been tested for the two UC studies unadjusted for smoking because the value of the pooled risk estimate was unclear.

We recalculated the RRs whenever raw data were provided. None of the recalculated estimates differed appreciably from those reported in the original research.

\section{Results}

\section{EXCLUDED STUDIES}

Table I shows a summary of the characteristics of excluded studies. Two studies ${ }^{13} 14$ specifically addressed recurrence not development of $\mathrm{CD}$ and were excluded. The Ramcharan study $^{15}$ did not report separate numbers for $\mathrm{CD}$ and UC. The Rhodes, ${ }^{16}$ Entrican, ${ }^{17}$ and Lichtarowicz $^{18}$ studies did not include appropriate control groups.

\section{INCLUDED STUDIES}

Of the reported studies (Tables II and III) nine had sufficient data to meet the eligibility criteria. The seven case-control studies ${ }^{20} 21$ 23-27 gathered information about 719 cases of inflammatory bowel disease $482 \mathrm{CD}$ and 237 UC) and 3198 controls, while the two cohort studies ${ }^{1922}$ followed 32673 users and 30379 women who did not use oral contraceptives.

The CIs for the RR estimate in seven of the eight reported studies of $C D$ included unity. The estimated RRs ranged from 0.7 to 2.5 . The pooled RR for cohort and case-control studies adjusted for smoking was $1.44(1.12$, $1 \cdot 86)$. The pooled estimate, unadjusted for smoking, was $1.68(0.97,2 \cdot 88)$.

For UC, in the four reported studies, the CIs for the RR again included unity. The RRs ranged from 0.7 to $2 \cdot 4$. The pooled adjusted RR was $1.29(0.94,1.77)$. The pooled estimate, unadjusted for smoking, as $1.68(0.97$, $2 \cdot 88$ ).

The RRs for each study and the pooled estimates are displayed in figures 1 and 2 . We did not show graphically the unadjusted estimated for UC because of the inconsistency of these results for only two studies. Summaries of all the studies included are presented in the Appendix.

\section{Discussion}

In this report we reviewed nine studies that investigate a possible link between oral contraceptive use and the development of $C D$ and UC. The studies were characterised by small sample size, selection of different comparison groups, and non-uniformity in adjusted variables, although existing heterogeneity between studies was small enough to be reasonably ignored. For the cohort studies, users and nonusers were recruited from a population attending family practice clinics. For case-controls studies, cases included were inflammatory bowel disease in- or outpatients and controls selected as non-relatives of inflammatory bowel disease cases. The purpose of oral contraceptive use was mainly for contraception. Combining results from selected studies seems appropriate.

In general, the reported estimates of an association between the use of oral contraceptives and either CD or UC are remarkably consistent in terms of the direction of the findings - an increased RR of CD and UC in oral

TABLE I Summary of studies excluded from the meta-analysis

\begin{tabular}{|c|c|c|}
\hline Authors & $\begin{array}{l}\text { Numbers } \\
(C D, U C)\end{array}$ & Comments \\
\hline Sutherland et al ${ }^{13}$ & 87 & $\begin{array}{l}\text { Retrospective/case-control; association between need of second surgery in CD in OC users and } \\
\text { non-users; adjusted for smoking, age, site. }\end{array}$ \\
\hline Wright et al ${ }^{14}$ & 162 & $\begin{array}{l}\text { Descriptive data on women with CD. Proportion of users and non-users in ileal, ileocaecal, } \\
\text { and colonic CD groups. No control group. }\end{array}$ \\
\hline Ramcharan et al ${ }^{15}$ & 107,165 & $\begin{array}{l}\text { Prospective, cohort study examining IBD incidence in OC users } v \text { never and ever users. } \\
\text { Cannot separate the } 2 \text { specific RRs for CD and UC. }\end{array}$ \\
\hline Rhodes et al ${ }^{16}$ & 100 & $\begin{array}{l}\text { OC use in consecutive outpatients with IBD. No controls (matching between colonic CD and } \\
\text { UC). Higher OC use rate in colonic CD than in UC patients. }\end{array}$ \\
\hline Entrican et $a l^{17}$ & 75 & $\begin{array}{l}\text { OC use in CD and UC patients with adequate data among randomly selected charts. No } \\
\text { control (OR users: non-users in both diseases). }\end{array}$ \\
\hline Lichtarowicz et al ${ }^{18}$ & 146 & $\begin{array}{l}\text { Retrospective study on menopause and contraception in women with CD. No control (\% of } \\
\text { users in CD: } 62 \% \text { is compared with the general population rate of OC use in } 24-28 \text { year old } \\
\text { married women: } 51 \% \text { ) }\end{array}$ \\
\hline $\begin{array}{l}\text { Tedesco et al } \\
\text { Conri et al }\end{array}$ & $\begin{array}{r}5 \\
10\end{array}$ & \\
\hline $\begin{array}{l}\text { Husson et } \text { al }^{8} \\
\text { Bourdais et } a l^{7}\end{array}$ & $\begin{array}{l}1 \\
1\end{array}$ & Case reports \\
\hline Heron et l $^{5}$ & 2 & \\
\hline
\end{tabular}

$\mathrm{CD}=$ Crohn's disease, $\mathrm{UC}=$ ulcerative colitis, $\mathrm{OC}=$ oral contraceptives, $\mathrm{IBD}=$ inflammatory bowel disease, $\mathrm{RR}=$ relative risk, $\mathrm{OR}=$ odds ratio. 
TABLE II Cohort studies included in the meta-analysis

\begin{tabular}{|c|c|c|c|}
\hline Study & Sample size & $R R(95 \% C I)$ & Comments \\
\hline $\begin{array}{l}\text { Vessey, } 1986^{19} \\
\text { (Oxford, UK) }\end{array}$ & $\begin{array}{l}17032 \text { women (9653 users) } \\
\text { attending family planning } \\
\text { clinics. Annual clinic, home, } \\
\text { mail, or phone questionnaire }\end{array}$ & $\begin{array}{l}\text { CD: } 1 \cdot 9(0 \cdot 7,4 \cdot 7)^{\star} \\
\text { CD: } 1 \cdot 5(0 \cdot 6,3 \cdot 8) \\
\text { UC: } 2 \cdot 5(1 \cdot 2,5 \cdot 1)^{\star} \\
\text { UC: } 2 \cdot 1(1 \cdot 0,4 \cdot 2)\end{array}$ & $\begin{array}{l}\text { Smoking status assessed at entry only. Trend } \\
\text { suggesting a positive association between } \\
\text { duration of OC use and incidence of CD. } \\
\text { Former users do not have increased relative risk } \\
\text { for both diseases. }\end{array}$ \\
\hline $\begin{array}{l}\text { Logan, } 1989^{22} \\
\text { (Nottingham, } \\
\text { UK) }\end{array}$ & $\begin{array}{l}46000 \text { women ( } 23000 \text { OC users }) \\
\text { attending general practician } \\
\text { clinics. Bi-annual visits. }\end{array}$ & $\begin{array}{l}\text { CD: } 1.5(0.8,3.1) \\
\text { UC: } 1.4(0.9,2.4)\end{array}$ & $\begin{array}{l}\text { Smoking status assessed at entry only. Former } \\
\text { users do not have increased risk for both } \\
\text { diseases. }\end{array}$ \\
\hline
\end{tabular}

*Unadjusted for smoking. $\mathrm{CD}=$ Crohn's disease; $\mathrm{UC}=$ ulcerative colitis; $\mathrm{OC}=$ oral contraceptives.

Pooled RR for CD: $1 \cdot 51(0 \cdot 86,2 \cdot 63)$ and UC: $1 \cdot 63(1 \cdot 06,2 \cdot 63)$.

contraceptive users, even when smoking is controlled. These increases are modest and in most reports, the individual CI did not reach statistical significance. This meta-analysis shows evidence of a modest increase of the RR for $\mathrm{CD}$ and $\mathrm{UC}$ in oral contraceptive users. These results suggest modest associations between oral contraceptive use and the development of CD and UC, but these associations are so weak that we cannot eliminate non-causal explanations.

The included studies could be classified as cohort or case-controls. Although each design offers weaknesses and strengths, the $R R$ estimates of each study were in the same range. Cohort studies can potentially elucidate temporal relationships between an exposure factor (oral contraceptive) and a disease (inflammatory bowel disease) and allow direct measurement of the incidence of disease in exposed and unexposed subjects. They do not seem to be well suited to evaluate this specific $R R$, however, because inflammatory bowel disease is rare. While, in practice, prospective cohort studies eliminate selection bias, the accuracy of risk measurement can be biased by either loss at follow up (restricted to $0.3 \%$ in Vessey study and unknown in Logan study) or by random misclassification of an exposure factor. For example, in both cohort studies smoking information was collected only at the entry. As we do not have information on the distribution of changes in this habit during the follow up period in the two groups (users and non-users), 'crude' RR and 'adjusted' RR can either overestimate or underestimate the true relative risk. Case-control studies are more efficient than cohort studies for rare diseases and common exposure factors such as inflammatory bowel disease and oral contraceptive use. Only two case-control studies ${ }^{21} 25$ had a sample size with sufficient power $(80 \%)$ to detect a significant increase in RR. Although misclassification bias may be of less concern, case-control studies are more prone to selection and recall bias. ${ }^{29}$

Bias may also have been present in the reports. In all studies using prevalent cases, recall bias may skew the $R R$ in favour of the exposure factor. Most authors were aware of this bias and selected only recently diagnosed inflammatory bowel disease or double checked the information collected in the two groups.

The selection of inpatients as either cases or controls could also have introduced a bias. ${ }^{32}$ Inflammatory bowel disease inpatients (cases) have more severe disease then their counterparts who are outpatients. ${ }^{23}$ Furthermore, they may be more prone to take oral contraceptives than the general inflammatory bowel disease population to prevent a pregnancy that might affect their clinical status. ${ }^{1}$ Oral contraceptive use in the control group formed by inpatients ${ }^{20} 23$ compared with a sample drawn from the general population may be different. These trends can underestimate or overestimate the true RR. The use of a second control group drawn from general population may give a relative degree of assurance that the risk estimate using an inpatient control group is not biased. ${ }^{32}$ In the Calkins study, ${ }^{20}$ the RR for the control group formed by inpatients was lower than the $R R$ for the control group drawn from general population.

The studies of Lashner et al 2426 were of matched case-control design, using friends as controls. Since the selection of controls should

TABLE III Case-control studies included in the meta-analysis

\begin{tabular}{|c|c|c|c|c|}
\hline \multirow[b]{2}{*}{ Study } & \multicolumn{2}{|l|}{ Sample size } & \multirow[b]{2}{*}{$R R(95 \% C I)$} & \multirow[b]{2}{*}{ Comments } \\
\hline & Cases & Controls & & \\
\hline $\begin{array}{l}\text { Lesko, } 1985^{23} \\
\quad \text { (North American cities) }\end{array}$ & $\begin{array}{l}57 \mathrm{CD} \\
\text { (inpatients) }\end{array}$ & $\begin{array}{l}2189 \text { Patients with infection, } \\
\text { trauma }\end{array}$ & $\mathrm{CD}: 1 \cdot 7(1 \cdot 0,3 \cdot 2)$ & $\begin{array}{l}\text { Trend for a positive association between duration of } O C \\
\text { use and } R R \text { for } C D \text {. Trend for a negative association } \\
\text { between time elapsed since last } O C \text { use and RR for } C D \text {. }\end{array}$ \\
\hline $\begin{array}{l}\text { Person, } 1993^{25} \\
\text { (Stockholm, } \\
\text { Sweden) }\end{array}$ & $\begin{array}{l}365 \text { IBD } \\
\quad \text { (inpatients) }\end{array}$ & $\begin{array}{l}390 \text { Individuals from a ran- } \\
\text { dom general population } \\
\text { sample stratified for age }\end{array}$ & $\begin{array}{l}\text { CD: } 1 \cdot 7(0.9,3 \cdot 2)^{\star} \\
\text { UC: } 1 \cdot 7(0.8,3 \cdot 3)^{\star}\end{array}$ & $\begin{array}{l}\text { Trend for an increased incidence of colonic involvement } \\
\text { compared to ileal and ileocaecal CD in OC users. No } \\
\text { preferential site for UC. }\end{array}$ \\
\hline $\begin{array}{l}\text { Calkins, } 1986^{20} \\
\text { (Baltimore, USA) } \\
\text { Lashner, 1989 } \\
\text { (Chicago, USA) }\end{array}$ & $\begin{array}{l}67 \mathrm{CD}, 32 \mathrm{UC} \\
\text { (inpatients) } \\
51 \mathrm{CD} \\
\text { (outpatients) }\end{array}$ & $\begin{array}{l}\text { Matched neighbours ( } 71 \text { for } \\
\text { CD, } 38 \text { for UC) } \\
51 \text { Neighbours and friends } \\
\text { (paired data) }\end{array}$ & $\begin{array}{l}\text { CD: } 1.6(0.6,4 \cdot 6)^{\star} \\
\text { UC: } 0.5(0 \cdot 1,3 \cdot 0)^{\star} \\
\text { CD: } 0 \cdot 7(0.3,1 \cdot 6)\end{array}$ & Size of UC group is too small to be interpreted properly. \\
\hline $\begin{array}{l}\text { Lashner, } 1990^{26} \\
\text { (Chicago, USA) }\end{array}$ & $\begin{array}{l}\text { 46 UC } \\
\text { (outpatients) }\end{array}$ & $\begin{array}{l}46 \text { Neighbours and friends } \\
\text { (paired data) }\end{array}$ & UC: $0.7(0.3,1.8)$ & $\begin{array}{l}\text { No dose-response effect. Smoking had no confounding or } \\
\text { interaction effect. Low power. }\end{array}$ \\
\hline $\begin{array}{l}\text { Katschinski, } 1993^{27} \\
\text { (Essen, Germany) }\end{array}$ & $\begin{array}{l}90 \text { CD } \\
\text { (outpatients) }\end{array}$ & $\begin{array}{l}90 \text { Individuals matched from } \\
\text { age from a random sample } \\
\text { (city population) }\end{array}$ & CD: $2 \cdot 5(1 \cdot 6,6 \cdot 6)$ & $\begin{array}{l}\text { Positive association between OC use and CD only for } \\
\text { non-smokers. }\end{array}$ \\
\hline $\begin{array}{l}\text { Sandler, } 1992^{21} \\
\text { (North Carolina, USA) }\end{array}$ & $184 \mathrm{CD}, 100 \mathrm{UC}$ & 276 Matched neighbours & $\begin{array}{l}\text { CD: } 1 \cdot 3(0 \cdot 8,2 \cdot 0) \\
\text { UC: } 1 \cdot 1(0 \cdot 6,1 \cdot 8)\end{array}$ & $\begin{array}{l}\text { Positive association between OC use and CD or UC only } \\
\text { for smokers. Trend for an increased risk of colonic CD } \\
\text { in OC users. No dose response-effect. }\end{array}$ \\
\hline
\end{tabular}

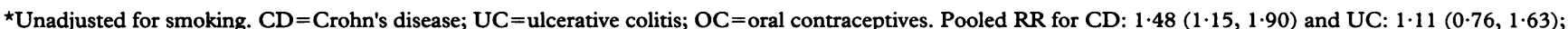
including Lashner studies 2426 . Pooled RR for CD: $1.59(1 \cdot 25,2 \cdot 03)$ and UC: $1 \cdot 25(1 \cdot 20-1 \cdot 63)$; excluding Lashner studies. 
A

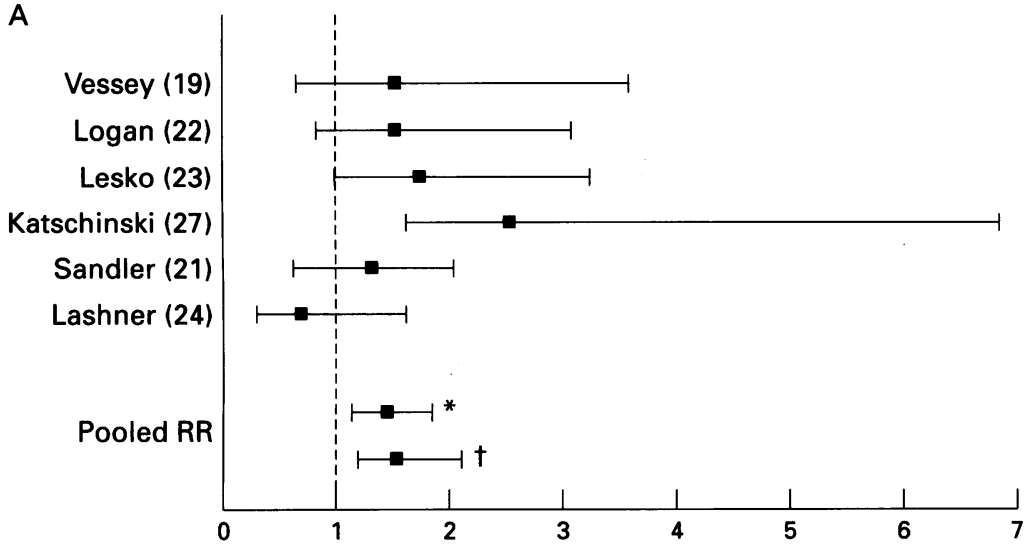

B

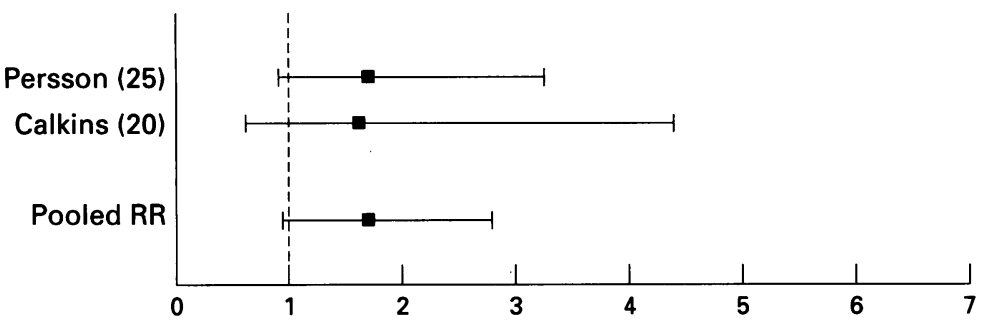

Figure 1: (A) Individual and pooled relative risks (RR) (95\% confidence intervals) for Crohn's disease adjusted for smoking. (B) Individual and pooled relative risks for Crohn's disease unadjusted for smoking. ${ }^{\star}$ Including Lashner study ${ }^{24}$; †excluding Lashner study.

be independent of the study factor within each stratum of matching factors, ${ }^{33}$ we were concerned that the use of friend nominated controls might be inappropriate. In their defence the authors noted that they validated the use of friend nominated controls by confirming the well known association between smoking and the development of CD in the study dataset. We elected to present the pooled results with and without these studies. Including or excluding the Chicago dataset, the recalculated $R R$ for developing either $C D$ or UC changed only minimally.

A major drawback in any meta-analysis is publication bias. ${ }^{34} 35$ The tendency of reviewers to favour studies with positive results has been documented previously. ${ }^{36}$ A potential correction for this bias would tend to put the significant association (between oral contraceptive use and CD or UC) closer to the null. A thorough search for registration of all studies addressing the specific association has been made in this meta-analysis. To our knowledge this seems to be the most practical solution to this problem, although we cannot be sure to have eliminated it.

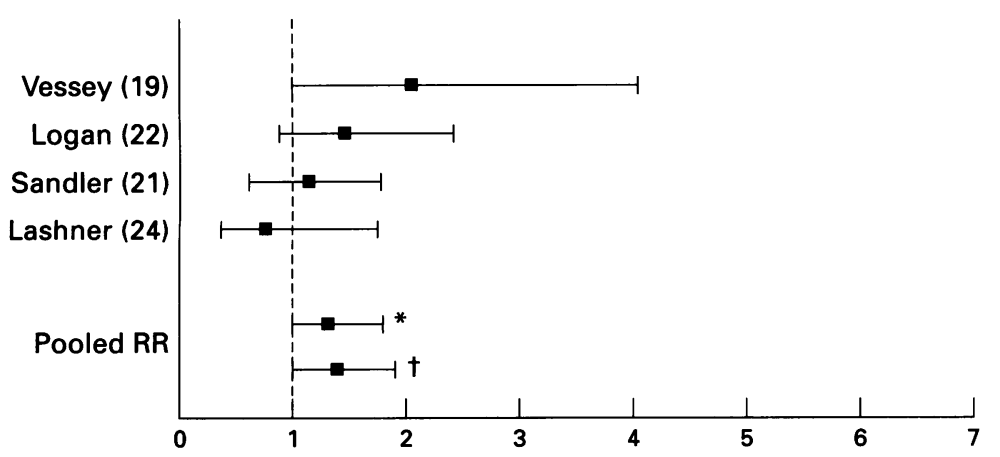

Figure 2: Individual and pooled relative risks (RR) (95\% confidence intervals) for ulcerative colitis adjusted for smoking. ${ }^{\star}$ Including Lashner study ${ }^{26}$; †excluding Lashner study.
When assessing the association between oral contraceptive use and inflammatory bowel disease, smoking must be considered as an effect modifier and a confounding factor. Smoking is protective in UC and is a positive risk factor for CD. Separation of risk estimates by CD and UC strata is thus mandatory. Smokers are more likely to take oral contraceptives than nonsmokers $^{12}$ and oral contraceptive users are more likely to smoke. ${ }^{22}$ Therefore, smoking may confound the effect of oral contraceptive on the development of inflammatory bowel disease and risk estimates must be adjusted for smoking when data are analysed. The effect of the adjustment for smoking was different among each individual study. Adjusting for smoking and other factors either increased $C D, 212527$ lowered, ${ }^{23}$ or did not change (UC) ${ }^{21}$ the estimates of RR. As most of these studies gave estimates of $R R$, adjusted for factors other than smoking, the real effect of this adjustment on the direction of the RR is unclear.

We were unable to show a dose-response effect (change in RR for developing CD and UC associated with change in exposure duration to oral contraceptive) or a difference between $R R$ estimates for ileal, ileo-colonic, or colonic CD. The data on these variables were either absent, inadequate (important proportions of unknown patients), without evidence of any statistical significance, or conflicting between studies.

\section{Appendix}

\section{STUDIES INCLUDED}

\section{Cohort studies}

Purpose: The two cohort studies examined the incidence of inflammatory bowel disease in users and non-users of oral contraceptives, and in smokers and non-smokers.

1.1 Vessey $1986 .^{19}$ Prospective study from Oxford, UK; includes 17032 women (9653 users), aged 25-39 years.

Lost to follow up: $0.3 \%$ per year (other than death, emigration).

Excluded: inflammatory bowel disease diagnosed before beginning of oral contraceptive use.

RR for CD unadjusted for smoking: 1.88 $(0 \cdot 74,4 \cdot 75)$.

RR for CD adjusted for smoking: 1.49 $(0 \cdot 58,3 \cdot 85)$.

RR for UC unadjusted for smoking: 2.50 $(1 \cdot 24,5 \cdot 06)$.

RR for UC adjusted for smoking: 2.05 $(1 \cdot 00,4 \cdot 20)$.

Comments: adjusted RRs fell short of statistical significance. Smoking status was assessed at entry only. The data are insufficient to assess a specific disease site association in both diseases. There is a trend suggesting a positive association between duration of oral contraceptive use and incidence of $\mathrm{CD}$ only. Former users ( $>2$ years) do not have increased RR for either disease.

1.2 Logan 1989.22 Prospective study from Nottingham, UK. Includes 23000 oral 
contraceptive users and 23000 non-users, aged $15-45$ years.

No data on those lost to follow up.

RR for CD adjusted for smoking: 1.51 $(0.75,3.05)$, ever smokers $v$ never smokers.

RR for UC adjusted for smoking: 1.44 $(0 \cdot 85,2 \cdot 45)$, ever smokers $v$ never smokers.

Comments: all RRs fell short of statistical significance, although the trend suggests a modest association for both diseases. Former users did not have an increased risk for both diseases oral contraceptive use was defined as continuous use for more than six months before beginning of symptoms. Smoking was assessed only at recruitment.

\section{Case-control studies}

2.1 Lesko $1985 .{ }^{23}$ Prospective study from several North American cities examining primarily the association between oral contraceptive use and inflammatory bowel disease.

Cases: 57 inpatients with CD ( $84 \%$ severe), $82 \%$ diagnosed with 3 months of interview.

Controls: 2189 inpatients with infection, trauma.

Excluded: gastrointestinal infection, pelvic inflammatory disease, UC.

RR estimate given by the author: $1.7(1.0$, 3.2); adjusted for age, race, religion, education, cigarette use, year of interview, geographic region, number of previous admissions.

Comments: data are not adequate to study smoking interaction. The study suggests that former oral contraceptive users are not at increased risk. There is a positive trend but not a significant association between duration of oral contraceptive use and $R R(p=0 \cdot 27)$. There is a negative trend but not a significant association between time elapsed since last oral contraceptive use and RR. Patients take oral contraceptive for different purposes (contraception, menstrual problems, sexual difficulties, endometriosis, and infertility). Forty two per cent of cases and $51 \%$ of controls were 40 years old or over and four per cent refused.

2.2 Persson 1993. ${ }^{25}$ Prospective study from Stockholm, Sweden, examining the association between inflammatory bowel disease on one hand and oral contraceptive use, physical activities, psoriasis, childhood gastrointestinal infections, family history, and having a bird as a pet on the other.

Cases: 365 new cases of inflammatory bowel disease/inpatients, aged 15-79 years.

Control: 390 randomly selected from population register stratified by age.

Excluded: outpatients and inpatients whose medical charts could not be reviewed within 4 years of diagnosis.

Multiple logistic regression $R R$ estimates given by the author: $R R$ for $C D=1 \cdot 7(0 \cdot 9,3 \cdot 2)$ (adjusted for age only; $\mathrm{RR}$ for $\mathrm{UC}=1.7(0.8$, 3.3) (adjusted for age only).

Comments: a user was defined as oral contraceptive use during the last 6 months. No information was given on oral contraceptive use duration or the time elapsed since last use. The study suggests an increased incidence for colonic involvement compared with ileal and ileocaecal involvement for $C D$ patients but there is overlap between the three specific confidence intervals. For UC there is no preferential site. Eighty per cent of patients responded to the questionnaire.

2.3 Calkins $1986 .{ }^{20}$ Prospective study from Baltimore examining the association of oral contraceptive use and the incidence of inflammatory bowel disease.

Cases: 66 inpatients from 1977 to 1979 , aged $10-60$ years

Control: (a) 67 inpatients matched for age, sex, race, discharge data for $C D ; 32$ for UC. (b) 71 neighbourhood controls matched for age, sex, race, neighbourhood of residence for $\mathrm{CD} ; 38$ for UC.

OR for CD: $1.63(0.58,4.57)$ unadjusted (neighbour control).

OR for UC: $0.52(0.09,3.01)$ unadjusted (neighbour control).

Comments: this study has not been published as a full size report. ORs are not adjusted for smoking. There are different purposes for oral contraceptive use (contraception, menstrual difficulties, hormone replacement). We do not know the age distribution of the population studied. There is a weak but not significant trend toward an increased RR in Crohn's disease for oral contraceptive users. The size of the ulcerative colitis group is too small to be interpreted properly.

2.4 Lashner 1989 and $1990 .^{2426}$ Two different prospective studies with the same design from Chicago, examining oral contraceptive use in CD (1989) and UC (1990) incident cases $v$ controls (paired data).

Cases: outpatients from 1981, aged $20-50$ years.

Controls: friends of cases in neighbourhood matched for age, race, sex, religion, residence, marital status, and parity.

Fifty one pairs (cases and controls) for CD and 46 pairs for UC.

Excluded: hysterectomy, contraindication to be exposed to oral contraceptive.

OR given by the author: $0.73(0.34,1.59)$ current users.

OR given by the author: $0.70(0.27,1.83)$ current users.

Comments: the OR estimates given by the author for the possible confounding effect of smoking computed with three different conditional regression models for the duration of use are not different from 1 . Authors conclude there is no evidence that oral contraceptive are a risk factor for either diseases because: (1) overall OR is not different from unity, (2) there is no association demonstrated by stratifying the data, and (3) there is no dose response effect. These studies are externally validated by the finding of a positive and a negative associations for smoking on one hand and CD and UC, respectively, on the other. Studies did not show an interaction or a confounding effect between oral contraceptive use and smoking. The minimal OR for oral contraceptive use if statistical 
significance is achieved ( $\alpha$ error of $5 \%, \beta$ error of $20 \%$ ) is around 2.8 for both studies. 2.5 Katschinski 1993. ${ }^{27}$ Retrospective and prospective study from Essen, Germany; examining an association between $\mathrm{CD}$ and oral contraceptive use and smoking.

Cases: 90 outpatients attending clinic from $1986-88$, among whom $61 \%$ were aged $<25$ years at disease onset.

Controls: 90 matched for age and randomly selected among city population.

Excluded: women with hysterectomy or those unable to take oral contraceptive.

$R R$ given by the author: $2.5(1.6,6.6)$ adjusted for smoking.

Comments: this study gives evidence of an association between oral contraceptive use and CD only for non-smokers. There is no evidence of a duration effect or a preferential site (non-significant trend toward ileal CD in oral contraceptive users). The study shows clearly an interaction effect of smoking and oral contraceptive use in inflammatory bowel disease. Eighty to $88 \%$ responded to the questionnaire.

2.6 Sandler 1992. ${ }^{21}$ Retrospective study from North Carolina examining the association between oral contraceptive use and inflammatory bowel disease as part of a larger study of potential environmental factors.

Cases: $184 \mathrm{CD}, 100 \mathrm{UC}$ from the Crohn's and Colitis Foundation of America; mean age CD 28 years, UC 33 years.

Controls: 276 neighbours matched for sex, age $(+/-5$ years), race: included some friends.

Excluded: onset of inflammatory bowel disease symptoms before menarche $(n=18)$, missing index date $(n=16)$, missing information on oral contraceptive use $(n=18)$.

Estimate of RR given by the author: 1.30 $(0 \cdot 85,2 \cdot 01)$ for $C D$, adjusted for smoking.

Estimate of RR given by the author: 1.08 $(0.63,1.85)$ for UC, adjusted for smoking.

Comments: there is interaction between oral contraceptive use and smoking for inflammatory bowel disease. There is an association between oral contraceptive use and inflammatory bowel disease only in smokers (inverse relationship compared with Katschinski report). There is a trend toward an increased risk of colonic CD in oral contraceptive users (ORs not adjusted for smoking and $14 \%$ of unknown site of disease in this specific group). For UC patients, the OR is not affected by adjusting for smoking or by stratifying for disease site. There is no evidence of a dose-response effect. Seventy four point six per cent of cases and $95.3 \%$ of controls responded to the questionnaire.

Dr Patrick Godet is a member of the Gastroenterology Unit of Notre-Dame Hospital, affiliated centre to the Université de Montréal, Montréal, Québec, Canada. This work has been funded by the Crohn's and Colitis Foundation of Canada.

1 Sandler RS, Golden AL. Epidemiology of Crohn's disease. 7 Clin Gastroenterol 1986; 8: 160-5.

2 Mendeloff AI, Calkins BM. The epidemiology of idiopathic inflammatory bowel disease. In: Kirshner JB, Shorter RG eds. Inflammatory bowel disease. Philadelphia, Lea and Fabinger, 1988.

3 Albert MB, Ginsberg AL. Oral contraceptives and Crohn's disease. Gastroenterology 1986; 99: 1097-8.

4 Delavierre P, Bourdais JP, Hureau J, Vayre P. Les accidents intestinaux au cours de l'emploi des contraceptifs oraux. Semaine des Hôpitaux de Paris 1976; 52: 1225-8.
5 Heron HC, Khubchandani IT, Trimpi HD, Sheets JA Stasik J. Evanescent colitis. Dis Colon Rectum 1981; 24: 555-61.

6 Kilpatrick ZM, Silverman JF, Betancourt E, Farman J, Lawson JP. Vascular occlusion of the colon and oral contraceptives. N Engl f Med 1968; 278: 438-40.

7 Bourdais JP, Delavierre P, Vayre P, Hureau J, Letailleur $M$ Maladie de Crohn ileo-colique apres emploi d'un contraceptif oral. Archives Françaises des Maladies de l'Appareil Digestif 1976; 65: 155-60.

8 Husson J. Iléite (Maladie de Crohn probable) et oestroprogestatifs. Semaine des Hôpitaux de Paris 1981; 57: progesta. 1750 .

9 Conri C, Schmitt B, Bache-Gabrielsen P, de Mascarel A Moreau F. Maladie de Crohn colique et contraception orale. Semaine des Hôpitaux de Paris 1979; 55: 1733-5.

10 Tedesco FJ, Valpolicelli NA, Moore FS. Oestrogen and progesterone associated colitis: a disorder with clinical and endoscopic features mimicking Crohn's disease. Gastrointest Endosc 1982; 26: 247-9.

11 Wakefield AJ, Sawyerr AM, Hudson M, Dhillon AP Pounder RE. Smoking, the oral contraceptive pill, and Crohn's disease. Dig Dis Sci 1991; 36: 1147-50.

12 Wakefield AJ, Dhillon AP, Rowles PM, Sawyerr AM, Pittilo RM, Lewis AAM, Pounder RE. Pathogenesis of Crohn's disease: Multifocal gastrointestinal infarction. Lancet 1989; ii: 1057-62.

13 Sutherland LR, Ramcharan S, Bryant H, Fick G. Effect of contraceptive use on reoperation following surgery for contraceptive use on reoperation following sur
Crohn's disease. Dig Dis Sci 1992; 37: 1377-82.

14 Wright JP. Factors influencing first relapse in patients with Crohn's disease. f Clin Gastroenterol 1992; 15: 12-6.

15 Ramcharan S. The Walnut Creek contraceptive drug study. A prospective study of the side effects of the oral contraceptives. Washington, DC: DHEW Publications, 1981: 74-562.

16 Rhodes JM, Cockel R, Allan RN, Hawker PC, Dawson J, Elias E. Colonic Crohn's disease and use of oral contraception. BMF 1984; 288: 595-6.

17 Entrican JH, Sircus W. Chronic inflammatory bowe disease, cigarette smoking, and use of oral contraceptives. BMF 1986; 292: 1464 .

18 Lichtarowicz A, Norman C, Calcraft B, Morris JS, Rhodes J, Mayberry J. A study of menopause, smoking, and con72: $267,623-31$.

19 Vessey M, Jewell D, Smith A, Yeates D, McPherson K. Chronic inflammatory bowel disease, cigarette smoking, and use of oral contraceptives: findings in a large cohort study of women of childbearing age. $B M F$ 1986; 292: $1101-3$.

20 Calkins BM, Mendeloff AI, Garland C. Inflammatory bowel disease in oral contraceptive users. Gastroenterology 1986; 91: 523-4.

21 Sandler RS, Wurzelmann JI, Lyles CM. Oral contraceptive use and the risk of inflammatory bowel disease. Epidemiology 1992; 3: 374-8.

22 Logan RFA, Kay CR. Oral contraception, smoking and inflammatory bowel disease - findings in the Royal inflammatory bowel disease - findings in the Royal 1989; 18: 105-7.

23 Lesko Sm, Kaufman DW, Rosenberg L, Helmrich SP, Miller DR, Stolley PD, Shapiro S. Evidence for an increased risk of Crohn's disease in oral contraceptive users. Gastroenterology 1985; 89: 1046-9.

24 Lashner BA, Kane SV, Hanauer SB. Lack of association between oral contraceptive use and Crohn's disease: a community-based matched case-control study. Gastroenterology 1989; 97: 1442-7.

25 Persson PG, Leijonmarck CE, Bernell O, Hellers G, Ahlbom A. Risk indicators for inflammatory bowel disease. Int 7 Epidemiol 1993; 22: 268-72.

26 Lashner BA, Kane SV, Hanauer SB. Lack of association between oral contraceptive use and ulcerative colitis. between oral contraceptive use

27 Karschinski B, Fingerle D, Scherbaum B, Goebell H. Ora contraceptive use and cigarette smoking in Crohn's disease. Dig Dis Sci 1993; 38: 1596-600.

28 Hennekens $\mathrm{CH}$, Buring JE. Case-Control studies. In: Mayrent SL, ed. Epidemiology in medicine. Boston: Little Brown 1987: 132-77.

29 Greenland S. Quantitative methods in the review of epidemiologic literature. Epidemiologic Rev 1987; 9: 1-30.

30 Halvorsen $\mathrm{K}$. Combining results from independent investigations: meta-analysis in medical research. In: Baylar JC gations: meta-analysis in medical research. In: Baylar JC, J Med 1992: 393-416.

31 DerSimonian R, Laird N. Meta-analysis in clinical trials. Controlled Clin Trials 1986; 7: 177-88.

32 West DW, Schuman KL, Lyon JL, Robison LM, Allred R. Differences in risk estimations from a hospital and a population-based case control study. Int f Epidemiol 1984; 13: 235

33 Flanders WD, Austin H. Possibility of selection bias in matched case-control studies using friend controls. $\mathrm{Am} \mathscr{f}$ Epidemiol 1986; 124: 150-3.

34 Naylor DC. Two cheers for meta-analysis: problems and opportunities in aggregating results of clinical trials. Can Med Assoc F 1988; 138: 891-5.

35 O'Brien PC. Meta-analysis: its role in medical research and in assessment of the association between low levels of cholesterol and excess mortality. Mayo Clin Proc 1993; 68: 891-93.

36 Dickersin K. The existence of publication bias and risk factors for its occurrence. $¥ A M A 1990 ; 263: 1385-9$. 